\title{
A (IN)CONSTITUCIONALIDADE DA APLICAÇÃO DA INTELIGÊNCIA ARTIFICIAL NO PROCESSO DECISÓRIO VIA PLATAFORMA RADAR
}

\section{THE (UN)CONSTITUTIONALITY OF THE APPLICATION OF ARTIFICIAL INTELLIGENCE IN DECISION MAKING VIA RADAR SOFTWARE}

\author{
Elisa Avelar Mattar* \\ Anne Shirley de Oliveira Rezende Martins ${ }^{* *}$
}

\begin{abstract}
RESUMO
O presente estudo objetiva demonstrar a forma como a inteligência artificial se expressa no âmbito do Tribunal de Justiça do Estado de Minas Gerais, de modo a averiguar a (in)congruência da implementação de sistemas de computação cognitiva com função decisória. Diante do cenário disruptivo em que se encontra o século XXI, perante o qual os meios tecnológicos vêm se apresentando cada vez mais aptos a realizar atividades humanas desenvolvidas pela função cognitiva, é primordial a imposição de um olhar crítico-reflexivo à natureza dúplice da implementação da inteligência artificial no Poder Judiciário. Isso porque, embora a razoável duração do processo e a segurança jurídica sejam aspectos constitucionais fundamentalíssimos para o pleno caminhar do Direito, o caráter irrefreável da modernização robótica desenvolvida através da inteligência artificial, na esfera jurídica, acaba por afastar a subjetividade das relações humanas, a objetividade dos critérios de julgamento, e a força normativa principiológica do neoconstitucionalismo. Assim, em atenção à implementação da Plataforma Radar, que opera através da computação cognitiva para a automatização de atividades jurisdicionais, inclusive para delegar a função decisória aos meios objetivotecnológicos, insta realizar um estudo acerca do funcionamento sistemático de tal aparato.
\end{abstract}

Palavras-chave: Inteligência artificial. Poder Judiciário. Função jurisdicional. Decisões judiciais. Automatização.

\begin{abstract}
The present study aims to demonstrate how artificial intelligence is expressed in the scope of the Court of Justice of the State of Minas Gerais, to ascertain the (in) congruence of the implementation of cognitive computing systems with decision-making functions. In the face of the disruptive scenario in the 21 st century, in which technological means are increasingly able to carry out human activities developed through cognitive function, it is essential to impose a critical-reflective look on the dual nature of implementation. of artificial intelligence in the Judiciary. This is because, although the reasonable duration of the process and legal security are fundamental constitutional aspects for the full walking of Law, the irrepressible character of robotic modernization developed through artificial intelligence, in the legal sphere, ends up removing the subjectivity of human relations, the objectivity of the judging criteria, and the

Artigo submetido em 15 de dezembro de 2020 e aprovado em 17 de março de 2021.

* Graduada em Direito pela Pontifícia Universidade Católica de Minas Gerais - PUC Minas. Pós-graduanda em Direito Digital pela Universidade do Estado do Rio de Janeiro - UERJ. Pesquisadora do Núcleo Acadêmico de Pesquisa, iniciação científica da Faculdade Mineira de Direito - PUC Minas, na linha de pesquisa "Lógica, Direito e Inteligência Artificial". E-mail: elisaavelarmattar@gmail.com

*** Doutora em Direito Pela Universidad de Deusto, Espanha. Mestre pela University of London, UK. Graduada pela Faculdade Mineira de Direito da PUC Minas. Professora da FMD. Advogada. E-mail: anne@ pucminas.br
\end{abstract}


Artigo: A (in)constitucionalidade da aplicação da inteligência artificial no processo decisório via plataforma radar

normative normative strength of neoconstitutionalism. Thus, because of the implementation of the Radar Platform, which operates through cognitive computing for the automation of jurisdictional activities, including delagating the decision-making function to objectivetechnological means, it calls for a study on the systematic functioning of such apparatus.

Keywords: Artificial intelligence. Judicial power. Jurisdictional function. Judicial decisions. Automation.

\section{INTRODUÇÃO}

A abordagem esboçada na presente pesquisa dirige-se à questão da computação cognitiva e sua pretensão de acometer o âmbito da decisão jurisdicional. Neste molde é que a temática ora investigada aborda a proposta do Tribunal de Justiça do Estado de Minas Gerais quanto à utilização da inteligência artificial no processo decisório com os desdobramentos da função jurisdicional, tendo como referencial teórico o Estado Democrático de Direito.

O problema de pesquisa enfrentado por este artigo pode ser exteriorizado através do seguinte questionamento: "Partindo da premissa de que a função jurisdicional, à luz do Estado Democrático de Direito, é composta pela subjetividade das relações humanas, objetividade dos critérios de julgamento e força normativa principiológica do neoconstitucionalismo, a proposta do Tribunal de Justiça do Estado de Minas Gerais em relação ao emprego da inteligência artificial no processo decisório é constitucional?

O objetivo geral do estudo esboçado neste artigo visa cotejar as razões que idealizaram o emprego da inteligência artificial no processo decisório, a fim de averiguar sua conexão com o Estado Democrático de Direito. Neste ponto é que se enfrenta diretamente as questões paradigmáticas da introdução da inteligência computacional no âmbito jurídico - e, mais precisamente, sob o aspecto jurisdicional.

A estruturação dos objetivos específicos parte de cada um dos elementos que se entende pertinentes integrantes do processo decisório democrático, estudando-se, portanto, a necessidade da análise detida do caso concreto, a imprescindibilidade do critério de subsunção imposto pela Lei de Introdução às Normas do Direito Brasileiro, e, ainda, a estrita harmonia entre estes elementos com a força normativa principiológica da Constituição da República Federativa do Brasil, de 1988.

Nesta linha, para atingir-se a finalidade almejada por este estudo, buscar-se-á a conceituação pertinente à inteligência artificial e suas implicações no âmbito da ciência da computação, em apertada sintonia com os parâmetros processuais-constitucionais da sociedade da informação.

Deste modo, no que tange ao recorte metodológico, muito embora este artigo se destine à área de concentração do Direito Constitucional, resta também acobertado pela multidisciplinariedade de caráter multidisciplinar, pois aborda definições do Direito Processual Civil, Engenharia de Software e Ciência da Computação.

Assim, através da pesquisa e revisão bibliográfica, a metodologia adotada para o desenvolvimento desta pesquisa é a exploratória, uma vez que busca propiciar entendimentos quanto à atual conexão entre a tecnologia e a ciência do Direito, percorrendo pelo estudo das diretrizes jurídico-constitucionais e da ciência da computação.

Por fim, incumbe salientar que este artigo não pretende esgotar o tema em questão, mas apenas impor um olhar crítico-reflexivo perante a natureza dúplice da computação cognitiva para fins de moldar o teor decisório, de modo a contribuir com o estudo desta abordagem tecnológica relativamente recente no âmbito jurídico.

\section{A FUNÇÃO JURISDICIONAL À LUZ DO ESTADO DEMOCRÁTICO DE DIREITO}


A assunção do Estado Democrático de Direito deu nova perspectiva à jurisdição, tendo em vista que, quando do Estado Liberal, esta era concentrada às mãos dos parlamentares, de modo que a supremacia da lei era realidade: os magistrados apenas aplicavam a lei ao caso concreto, sem poder, de fato, interpretá-la. Neste contexto, aduz Luiz Guilherme Marinoni:

\begin{abstract}
Porém, como o direito foi resumido à lei e sua validade conectada exclusivamente com a autoridade da fonte de sua produção, restou impossível controlar os abusos da legislação. Se a lei vale em razão da autoridade que a edita, independentemente da sua correlação com os princípios de justiça, não há como direcionar a produção do direito aos reais valores da sociedade. Daí se ter como certo que a teoria de Montesquieu, embora tenha se voltado contra os abusos do ancien régime, lançou as sementes da tirania do Legislativo. (MARINONI, 2017, p. 18, grifos do autor).
\end{abstract}

Seguindo esta asserção, verifica-se que o período da supremacia legislativa aspirava por uma lei abstrata com potencial abrangência em toda e qualquer lide, bastando sua mera aplicação por parte do magistrado. Neste molde, os conflitos inerentes à vida em sociedade eram dirimidos de maneira objetiva, partindo do pressuposto de que o julgamento deveria ser, pura e unicamente, "um texto exato da lei." (MONTESQUIEU, 1748).

Contudo, transcorrida a era da absoluta primazia do Parlamento e da Lei, fora erigido o Estado Democrático de Direito. Assim sendo, a concepção de jurisdição passou a se dar, precipuamente, na função do Estado de se atentar à subjetividade dos direitos privados violados, componentes da lide que cuidou de movimentar o Poder Judiciário - inerte por natureza - e suas devidas implicações nos parâmetros principiológicos do neoconstitucionalismo.

Constata-se, portanto, que a percepção atual da jurisdição em muito se distingue da passada, na medida que, hoje, a referida função é exercício (e função típica) do Poder Judiciário, e carrega consigo a essência da interpretação da lei pelo magistrado antes de aplicá-la ao caso concreto, porém, se atentando, incondicionalmente, aos princípios previstos pela Constituição da República de 1988 (BRASIL, 1988). Uma vez reconhecida a força normativa principiológica da Carta Magna, resta consagrada a conformidade necessária entre o direito e a moral, conduzindo o Poder Judiciário à atuação em consonância com os valores e garantias constitucionais (BRASIL, 1988). Enriquecedoras são as afirmações de Maria Helena Diniz no que tange à necessária análise do caso concreto para efetivação da função jurisdicional à luz do Estado Democrático de Direito:

O momento da aplicação da norma é característico do direito positivo. Isto porque as normas positivas existem, fundamentalmente, para ser aplicadas por um órgão competente, juiz, tribunal, autoridade administrativa ou particular. A aplicação do direito é, portanto, decorrência de competência legal. O juiz aplica as normas gerais ao sentenciar; o legislador, ao editar leis, aplica a Constituição; o Poder Executivo, ao emitir decretos, aplica norma constitucional; o administrador ou funcionário público aplica sempre normas gerais ao ditar atos administrativos; simples particulares aplicam norma geral ao fazer seus contratos e testamentos. Ater-nos-emos aqui, principalmente, à aplicação feita pelo Poder Judiciário que consiste em submeter um caso particular ao império de uma norma jurídica. (DINIZ, 2003, p. 409, grifo nosso)

Reconhece-se, contudo, a inexistência, no Estado Democrático de Direito, de previsão legislativa para todo e qualquer litígio que venha a ocorrer. Isso se dá em razão da subjetividade das relações humanas - primeiro desdobramento da função jurisdicional. Pensa-se da seguinte forma: caso a legislação brasileira pretendesse abranger todos os potenciais litígios entre praticamente duzentas e dez milhões de pessoas, as leis seriam editadas a todo momento. Neste diapasão, o artigo $4^{\circ}$, da Lei de Introdução às Normas do Direito Brasileiro obriga o juiz a aplicação, respectivamente, da analogia, dos costumes, ou, ainda, dos princípios gerais de 
Artigo: A (in)constitucionalidade da aplicação da inteligência artificial no processo decisório via plataforma radar

direito, nos casos em que haja lacuna legislativa - imprimindo clareza quanto ao segundo desdobramento da função jurisdicional, a objetividade dos critérios de julgamento (BRASIL, 1942).

Justificando-se, portanto, no extenso acervo legislativo pátrio, e, ainda, na ausência de previsão legal para toda e qualquer lide, o ordenamento jurídico deparou-se com a imprescindibilidade da fundamentação das decisões judiciais, de tal sorte que agregou ao seu rol de princípios constitucionais o que bem consta no artigo 93, inciso IX, da Constituição da República (BRASIL, 1988). Afinal, uma vez que há, no Estado Democrático de Direito, a possibilidade da interpretação da lei pelo magistrado às margens do caso concreto, a fundamentação do teor decisório se revela crucial. Do contrário, o ativismo judicial acabaria por eivar o sistema processual brasileiro.

De acordo com os ensinamentos de Nunes, Bahia e Pedron (2020), o dever de fundamentação das decisões judiciais, que, vale a ênfase, encontra respaldo, também, no Código de Processo Civil, materializa-se em um instrumento contra o arbítrio e a discricionaridade judicial. Assim, trazendo à tona a tênue linha entre as decisões fundamentadas (isto é, decisões que, para além de motivarem o decisum, demonstram a razão pela qual deixaram de acolher a interpretação da lei ofertada pela parte sucumbente) e o processo democrático, atuando, as primeiras, como pressupostos de efetividade do segundo.

Há de se concluir, contudo, que o entendimento da função jurisdicional, nos parâmetros necessários ao efetivo processo democrático, compreende, inexoravelmente, a subjetividade das relações humanas (precursoras da concretude dos casos que retiram o Poder Judiciário da inércia), a objetividade dos critérios de julgamento, e, como terceiro desdobramento da função jurisdicional, a força normativa principiológica do neoconstitucionalismo - consolidada neste estudo, principalmente, através do dever constitucional de fundamentação das decisões jurisdicionais. Tais preceitos, se ausentes, impossibilitam a prestação efetiva da atribuição típica do Poder Judiciário à luz do Estado Democrático de Direito.

\section{INTELIGÊNCIA ARTIFICIAL}

Elaborada a delineação no que tange ao referencial teórico e a contextualização da função jurisdicional em sua essência, passa-se ao estudo da inteligência artificial. Isto pois, propõe o presente artigo, a análise da constitucionalidade do emprego desta em função daquela.

A busca pela conceituação do termo "inteligência artificial" é árdua, uma vez que não há, de forma unânime, uma delimitação exata do que seria esse eixo da ciência da computação. Sabe-se, contudo, que anterior à definição da inteligência artificial, é relevante o conhecimento do conceito da palavra "inteligência", na sua maneira mais simplória possível. Dessa forma, frise-se que o vocábulo em questão é oriundo do latim intelligentia ou intellectus, que, por seu turno, provêm do verbo intellego, de modo a exteriorizar o compreender, o conhecer, o perceber, o ver, o discernir e o associar, ações estas, comumente relacionadas à atividade cerebral.

Nesta mesma linha, aduzem Martins, Reis e Andrade (2020), trabalhando Parfit (2011) e Brandom (2009), que a distinção dos seres humanos para com os demais seres vivos se dá exatamente por sua aptidão para raciocinar, compreender, responder, e até mesmo refutar as circunstâncias inerentes à vida e ao mundo. Assim, conforme certifica-se mediante a delineação racionalista quanto aos agentes humanos, a compreensão de que estes são racionais, presume, necessariamente, sua aptidão para estruturar razões de maneira inferencial - isto é, obter uma conclusão através de um processo cognitivo perante o qual esteve presente uma asserção relativa a algo até então desconhecido pelo agente.

Alcançada, desta maneira, a essência do vocábulo "inteligência", o foco do presente tópico passa a se dar em sua estrita conexão com a esfera robótica. Para este fim, perpassa-se 
pelo processo de automatização, e também por conceitos relevantes para um entendimento adequado quanto à problemática sugerida por este artigo.

Apresentam-se as rupturas paradigmáticas e o imediatismo alguns dos principais traços do contexto humano-social atual. Em decorrência do cenário de expansão tecnológica em que se encontra a sociedade da informação, as necessidades dos indivíduos se modificaram, de forma que a busca pela agilidade, sob qualquer aspecto, é praticamente ilimitada. Nas palavras de Junger et al.:

\begin{abstract}
Atualmente, vivemos numa sociedade totalmente apressada, em que tudo se quer de imediato, e que quase tudo pode ser conectado, interligado, fazer parte de uma só rede, logo, há interatividade e comunicação instantânea entre transmissor e receptor, através de dispositivos eletrônicos, sejam smartphones, Smart TVs, ou outros, por exemplo. (JUNGER, Alex Paubel et al., 2018, p. 13, grifos dos autores).
\end{abstract}

Neste passo é que surge o desígnio da implantação dos ágeis sistemas de inteligência artificial, com potencial aptidão para realizar atividades humanas desenvolvidas através de sua (inerente) função cognitiva. De acordo com a intelecção de Edmundo Veras (SANTOS FILHO, 2019 apud ROSA; GUASQUE, 2020), os recursos de inteligência artificial são programas computacionais criados para aprendizagem e generalização de processos análogos ao raciocínio humano. Ou seja, para o efetivo funcionamento de tais aparatos, é imprescindível que haja uma instrução do homem para com a máquina.

Ainda segundo o intelecto de Veras (SANTOS FILHO, 2019 apud ROSA; GUASQUE, 2020), a inteligência artificial pode ser descrita, em linhas gerais, como o ramo da ciência da computação apto a reproduzir a cognição que, até o momento de seu emprego, era própria do cérebro humano. No mesmo sentido é o entendimento de Medeiros (2019), que define a inteligência artificial como uma tecnologia embasada na simulação, pela máquina, de atividades humanas, de modo a configurar a chamada automatização, produzindo, portanto, o conhecimento de maneira artificial.

Procedendo-se destes conceitos, plausível é a definição do termo "inteligência artificial" como um campo da ciência computacional que provoca enorme expectativa à sociedade do século XXI - sociedade da informação - no tocante ao seu expressivo sucesso na reprodução de tarefas cognitivas. Isso pois, de fato, as máquinas vêm se apresentando cada vez mais aptas a mimetizar o comportamento humano-inteligente, esculpindo, sob medida, o caráter irrefreável da modernização robótica.

\title{
4 A RAZÃO DE SER COMPUTAÇÃO JURÍDICO-COGNITIVA
}

Ainda em sede tecnológica, proceder-se-á ao estudo dos princípios constitucionais que garantem aos jurisdicionados a razoável duração do processo e a segurança jurídica, entendendo-se estes atuarem como corolários para a invasão high-tech na área do Direito.

A partir das reflexões de Lemes (2019), a promulgação da Constituição vigente, em outubro de 1988, foi preceito fundamental para a redemocratização formal do Brasil (que, naquele momento, acabara de se ver livre, após 21 anos, do regime ditatorial), de modo a viabilizar uma nova proposição no que tange ao processo constitucional-democrático. Assim sendo, a compreensão acerca da base normativa principiológica enraizada na Constituição da República de 1988, desde o final da década de 1990 (ocasião em que fora inaugurado o neoliberalismo processual) passou a ser indispensável. Nesta esteira, pretendendo conferir lógica ao vocábulo "princípio", endossa Humberto Ávila:

As regras podem ser dissociadas dos princípios quanto ao modo como prescrevem o comportamento. Enquanto as regras são normas imediatamente descritivas, na medida 
Artigo: A (in)constitucionalidade da aplicação da inteligência artificial no processo decisório via plataforma radar

em que estabelecem obrigações, permissões e proibições mediante a descrição da conduta a ser adotada, os princípios são normas imediatamente finalísticas, já que estabelecem um estado de coisas para cuja realização é necessária a adoção de determinados comportamentos. Os princípios são normas cuja qualidade frontal é, justamente, a determinação da realização de um fim juridicamente relevante, ao passo que característica dianteira das regras é a previsão do comportamento. (ÁVILA, 2012, p. 71, grifos do autor).

A Carta Magna de 1988, neste sentido, imprimiu nova roupagem no tocante às garantias processuais-constitucionais, ofertando, em seu artigo $5^{\circ}$, setenta e oito incisos que esculpem o seu extenso leque de direitos e garantias constitucionais (BRASIL, 1988). No interior do dispositivo em questão, encontram respaldo, dentre outros inúmeros, o direito à duração razoável do processo e à estabilidade dos negócios jurídicos (SILVA, 2005), este último, amplamente conhecido como "princípio da segurança jurídica".

Instituído pela Emenda Constitucional 45/2004, o inciso LXXVIII, do artigo $5^{\circ}$, da Constituição da República de 1988, garante que, tanto no âmbito judicial, bem como na esfera administrativa, serão assegurados os meios que garantem a celeridade da tramitação processual e sua duração razoável (BRASIL, 1988). Tal princípio, portanto, corrobora com a efetivação do acesso à justiça e prestação jurisdicional. É partindo deste pressuposto que dispõe Humberto Theodoro Júnior:

É evidente que sem efetividade, no concernente resultado processual cotejado com o direito material ofendido, não se pode pensar em processo justo. Não sendo rápida a resposta do juízo para a pacificação do litígio, a tutela não se revela efetiva. Ainda que afinal se reconheça e proteja o direito violado, ao longo do tempo em que o titular, no aguardo do provimento judicial, permaneceu privado de seu bem jurídico, sem razão plausível, somente pode ser visto como uma grande injustiça. (THEODORO JÚNIOR, 2015, p. 134, grifo nosso).

Reconhece-se, a partir desta asserção, a atuação do princípio da razoável duração do processo como requisito intrínseco do processo legal, devendo o Estado combater a morosidade judicial, sob pena de serem os jurisdicionados acometidos pela injustiça. Neste sentido, trata-se o direito em questão de um dever primário e fundamental do Poder Judiciário, inerente ao processo à luz do Estado Democrático de Direito.

A implementação da computação cognitiva na esfera jurídica encontra respaldo nesta garantia constitucional, tendo em vista que seus softwares de automatização da produção, tanto de peças jurídicas, bem como de decisões jurisdicionais, são substancialmente mais rápidos que os humanos. É exatamente nesta medida que a tecnologia assegura uma tramitação mais ágil, de modo a suprir a (justa) sede por celeridade da geração do século XXI.

A superioridade temporal da máquina em face dos humanos pode ser facilmente comprovada mediante a informação, prestada pela Ministra Cármen Lúcia, de que a atividade de conversão de imagens em textos, executada pelo software (Projeto Victor) que automatiza as decisões do Supremo Tribunal Federal, é realizada em cinco segundos, enquanto que, se realizada por um servidor, gastaria cerca de três horas. No mesmo sentido, noticiou o Ministro Dias Toffoli que os testes, até então efetuados, apontaram que o Projeto Victor reconhece os casos de recursos extraordinários ou de agravos em recursos extraordinários, com $85 \%$ de êxito, em cinco segundos, ao passo que um servidor levaria entre quarenta minutos e uma hora para a conclusão de tal atividade (MARTINS et al., 2020).

Ainda de modo a corroborar com a tese de que o princípio da razoável duração do processo foi crucial para a implantação de ferramentas de computação cognitiva no âmbito 
jurídico, em 30 de agosto de 2018, o site do Supremo Tribunal Federal publicou notícia referente ao início do funcionamento do sistema inteligente ora tratado, informando que o intuito de seu emprego é ofertar resposta jurisdicional mais veloz. Assim, vê-se:

A presidente do Supremo Tribunal Federal (STF), ministra Cármen Lúcia, anunciou ao final da sessão plenária desta quinta-feira (30) que já está em funcionamento o Projeto VICTOR, que utiliza Inteligência Artificial (IA) para aumentar a eficiência e a velocidade de avaliação judicial dos processos que chegam ao tribunal. Desenvolvido em parceria com a Universidade de Brasília - UnB, o projeto é o mais relevante no âmbito acadêmico brasileiro relacionado à aplicação da IA no Direito. (BRASIL, 2018, grifo nosso).

Denota-se, nesta toada, que o emprego de ferramentas de automatização do trabalho, até então convencional, dos juristas, por certo, agregou vantagem ao mundo jurisdicional. A produtividade, como fora demonstrado, apresentou significativa melhora, comprovando o fato de que o emprego de softwares para efetivar a garantia constitucional da razoável duração do processo ocasionou em maior rendimento no trabalho dos tribunais.

Ademais, de acordo com Rômulo Valentini (2017), a compilação sistematizada do acervo de decisões, acessível através do big data, aponta que um profissional do Direito com conhecimento jurídico escasso é capaz de apresentar, "em tempo igual ou inferior", minutas de padrões semelhantes às dos grandes conhecedores da ciência do Direito. Em continuidade à sua linha de raciocínio, alega que as rupturas paradigmáticas provocaram mudança sistemática do trabalho jurídico, que era, a priori, "artesanal", e agora passou a ser "industrial", sendo a agilidade característica ímpar deste último.

O que se percebe através das elucidações supramencionadas, é que o trabalho de massa dos magistrados, por ele denominado "industrial", seria vantajoso para o terreno jurídico, uma vez que mais célere.

Por outro lado, objetivando-se o pleno caminhar do processo democrático, a Carta de 1988 assegurou aos jurisdicionados a estabilidade dos direitos subjetivos, que é advinda, linearmente, do princípio da segurança jurídica. Isso porque, em meio a tamanho acervo legislativo no tempo (e no espaço - Brasil), surge a necessidade de tornar possível que as pessoas tenham um conhecimento prévio das potenciais repercussões de seu comportamento à luz do direito de liberdade que lhe foi reconhecido.

O princípio em questão encontra respaldo no inciso XXXVI, do artigo $5^{\circ}$, da lei constitucional, que garante a previsibilidade dos resultados que pode acarretar uma conduta e o não prejuízo do direito adquirido, da coisa julgada, e do ato jurídico perfeito (BRASIL, 1988). É baseando-se nessas premissas que aduz José Afonso da Silva:

A segurança jurídica consiste no "conjunto de condições que tornam possível às pessoas o conhecimento antecipado e reflexivo das consequências diretas de seus atos e de seus fatos à luz da liberdade reconhecida". Uma importante condição da segurança jurídica está na relativa certeza que os indivíduos têm de que as relações realizadas sob o império de uma norma devem perdurar ainda quando tal norma seja substituída. (SILVA, 2005, p. 433, grifos do autor).

Sobre este tema, o Código de Processo Civil de 2015 não poupou esforços para a uniformização jurisprudencial, valendo-se de institutos processuais voltados a assemelhar os julgamentos das demandas ajuizadas (BRASIL, 2015). A esse respeito, assinala Abi-Chahine (2015), que as últimas alterações processuais evidenciaram a valorização dos sistemas de 
Artigo: A (in)constitucionalidade da aplicação da inteligência artificial no processo decisório via plataforma radar

precedentes judiciais, que permitem a aplicação, em processos supostamente semelhantes, de decisões estabelecedoras de determinada tese jurídica.

Neste contexto, enfatiza-se a existência, nos atuais moldes processuais brasileiros, de diversos institutos cujo escopo é o estabelecimento de precedentes vinculantes, tais como o Recurso Extraordinário, o Recurso Especial, o Incidente de Resolução de Demandas Repetitivas e o Incidente de Assunção de Competência. Ressalta-se, neste seguimento, que a subsistência de mecanismos que uniformizam a jurisprudência conduz o discernimento prévio das implicações que os atos dos jurisdicionados podem gerar, agregando, portanto, direta ligação desta com a segurança jurídica.

Quando do estudo dos sistemas geradores de precedentes do Direito Processual brasileiro, é possível que se trace um paralelo entre estes e determinadas ferramentas de inteligência artificial utilizadas por alguns tribunais pátrios, que, assim como o Recurso Extraordinário, o Recurso Especial, o Incidente de Resolução de Demandas Repetitivas e o Incidente de Assunção de Competência, atribuem repercussão coletiva ao julgamento de demandas individuais. Isso pois, de fácil entendimento, é a relação entre estes e o princípio da segurança jurídica, garantido através do inciso XXXVI, do artigo $5^{\circ}$, da lei constitucional (BRASIL, 1988).

A pressuposição que ora pretende-se demonstrar - o direito à estabilidade dos negócios jurídicos como corolário para o emprego da inteligência artificial na esfera do Direito - alcança amparo nas afirmações de Valentini (2017), no sentido de que, sendo garantidas as discussões jurídicas e as apreciações acerca dos acervos probatórios dos processos através da operação humana, o emprego das máquinas para a atividade de decidir em si, promove a necessária segurança do teor decisório. Fortalecendo esta presunção, Pereira e Burmann (2020), alegam que, mediante o armazenamento de dados gerados por modelagens anteriores no big data, são proporcionadas transparência e segurança no que tange aos fundamentos que conduziram o dispositivo.

As asserções supramencionadas cuidam, portanto, de conferir acerto à tese de que o princípio constitucional da segurança jurídica teve profícuo papel na decisão de implementar meios artificiais para a produção do trabalho jurisdicional, visando maior eficiência. Afinal de contas, de fato a previsibilidade do teor decisório promovida pelo acúmulo de dados no big data, alavanca incontestável confiabilidade à resposta jurisdicional.

Com efeito, alcança-se o pretendido no presente tópico da pesquisa: as garantias constitucionais asseguradas pelos incisos LXXVIII e XXXVI, do artigo $5^{\circ}$, da Constituição da República de 1988 foram primordiais para o emprego de softwares automatizadores das mais variadas formas de trabalho jurídico.

\section{O DIÁlOGO ENTRE A SUBJETIVIDADE DAS RELAÇÕES HUMANAS, A OBJETIVIDADE DOS CRITÉRIOS DE JULGAMENTO E A FORÇA NORMATIVA PRINCIPIOLÓGICA DO NEOCONSTITUCIONALISMO}

Para que se entenda o diálogo lógico entre os três aspectos que serão ora tratados, é necessário atentar-se à função jurisdicional como um exercício de competência dos órgãos que compõem o Poder Judiciário. Assim, considera-se que esta atividade é inaugurada no momento em que há o ajuizamento de uma ação, e se encerra na ocasião em que a lide é resolvida, isto é, através da tomada de decisão jurisdicional.

Sugere, pois, a presente pesquisa, a análise dos desdobramentos existentes durante o exercício desta função - da distribuição da ação à tomada de decisão. Este é o processo decisório a que se refere o título deste artigo. Diante deste contexto, entende-se necessário o estudo de cada um dos aspectos em questão, reafirmando, dado que já foram abordados no segundo capítulo, as definições que se entende pertinentes acerca da subjetividade das relações 
humanas, da objetividade dos critérios de julgamento, e da força normativa principiológica do neoconstitucioalismo, traçando-se um paralelo entre estes e suas potenciais implicações quando da automatização das decisões jurisdicionais.

Ao se pensar a subjetividade das relações humanas, elemento que tanto se menciona neste trabalho, deve-se presumir sua essência na análise detida do caso concreto. Tal fato se dá em razão do caráter de generalidade e abstração das leis, de modo que estas não foram criadas para um conflito em específico - são feitas para atender pessoas e casos indefinidos - mas, para, através da subsunção, haver a possibilidade de adequarem-se aos moldes dos casos concretos.

Entende-se, isto posto, o âmago do Poder Judiciário se dar exatamente nesta adequação da norma jurídica ao subjetivíssimo caso concreto, de maneira que a generalização empregue pelas máquinas para o julgamento das lides desconsidera este trabalho - fruto do esforço de centenas de anos, desde o Estado Absolutista, quando não se falava em direitos e liberdades individuais, até o Estado Democrático de Direito, que zela pelas inúmeras garantias constitucionais, e, consequentemente, pela subjetividade dos direitos privados violados. É exatamente neste norte que salientam Oliveira e Cardoso:

O processo de tomada de decisão é uma das atividades mais importantes do Direito. Embora se preocupe com o conhecimento abstrato, o Direito, geralmente, se preocupa mais com a solução para problemas particulares. (OLIVEIRA; CARDOSO, 2015, p. 134, grifo nosso).

Certo é que a subjetividade das relações humanas está intrinsecamente ligada com o segundo elemento deste estudo: a objetividade dos critérios de julgamento. Isto em decorrência, também, da denominada subsunção, prevista através do artigo $4^{\circ}$, da Lei de Introdução às Normas do Direito Brasileiro (BRASIL, 1942). Se não, veja-se: uma vez que há previsão legal quanto à ordem dos critérios de julgamento diante dos casos eivados pela lacuna legislativa, resta descartada a hipótese de composição de lides fundada em ordem singular (SILVA, 2005).

Com base nestas premissas, questiona-se se o emprego das máquinas no processo decisório - nos casos em que sua tecnologia é utilizada para, de fato, esculpir o teor decisório do conflito - não ofenderia o princípio da subsunção previsto pela Lei de Introdução às Normas do Direito Brasileiro. Afinal, dentre as hipóteses de resolução dos conflitos, nunca fora mencionada a aplicação da tecnologia.

No que tange à força normativa principiológica do neoconstitucionalismo, é indubitável seu profícuo papel no processo decisório democrático. Este entendimento decorre da análise evolutiva do Estado, que, desde o Absolutista, perpassando pelo Liberal e Social, até que, enfim, chegando ao Democrático de Direito, se desenvolveu, principalmente, quanto ao parâmetro principiológico.

Neste contexto, o Estado Democrático de Direito é marcado e conhecido por sua dedicação às garantias constitucionais, tendo a Constituição da República de 1988 trabalhado bastante o seu repertório principiológico. Dessa forma, para que o processo decisório seja considerado constitucionalmente adequado, conclui-se imperiosa a atenção aos princípios constitucionais, e suas devidas aplicações à subjetividade das lides.

A partir destas considerações, deve-se refletir acerca do uso da tecnologia pelo órgão jurisdicional à luz das garantias constitucionais. Em outras palavras, dirigindo a atenção à pretensão da tecnologia em filiar-se à esfera jurisdicional, pertinente que a averiguação da consonância entre os softwares e as garantias constitucionais, a título exemplificativo, do contraditório e da fundamentação das decisões judiciais. Em verdade, conforme salientam Fioratto e Brêtas há uma estrita relação entre estas garantias:

No Estado Democrático de Direito, o contraditório deve ser compreendido como princípio de influência e de não surpresa, tornando-se base para o 
Artigo: A (in)constitucionalidade da aplicação da inteligência artificial no processo decisório via plataforma radar

princípio da fundamentação da decisão e para o exercício do controle da argumentação utilizada pelo juiz. Se houver a restrição ou a supressão da garantia constitucional do contraditório, certamente, haverá a violação da garantia constitucional da fundamentação das decisões. Ao passo que se o princípio da fundamentação das decisões for respeitado, o contraditório também foi respeitado no trâmite processual. (FIORATTO; BRÊTAS, 2010, p. 132).

Com base nesta asserção, deve-se refletir se a máquina é capaz de fundamentar - legal reasoning - as decisões por ela tomadas. Deste modo, no intuito de averiguar a existência de cognição na esfera da inteligência artificial, o matemático inglês Alan Mathison Turing formulou o denominado teste de Turing, que é um exame baseado no "jogo da imitação". Assim, a constatação, através deste teste, de que o trabalho da máquina para determinado fim é indistinguível daquele efetuado pelo cérebro humano, cuida de clarear a questão acerca da cognição computacional.

O teste de Turing, nesta linha, acabou por distinguir duas espécies de inteligência artificial. A primeira - IA fraca - resolve problemas simulando o pensamento humano, como se inteligente fosse. Por seu turno, a segunda - IA forte - de fato pensa, agindo, portanto, como um ser inteligente (VALENTINI, 2017).

Contrarrazoando o teste de Turing, Searle desenvolveu um argumento conhecido como "quarto chinês". A refutação deste confere a compreensão de que os computadores estão inaptos ao pensamento nos parâmetros cerebrais humanos. Tal conclusão se dá em razão do seguinte fato: o "quarto chinês", considera a situação hipotética de que um homem e uma máquina devem compreender, através da leitura de um manual, o que uma língua até então desconhecida deseja transmitir. Nesta toada, o ser humano conseguirá, a partir do manual, decifrar o que transmite o idioma por ele desconhecido - em decorrência de sua aptidão para estruturar razões de maneira inferencial. Lado outro, a máquina será incapaz de compreender o que diz a língua por ela desconhecida, uma vez que necessita da linguagem programática para que seja realizado o processo de automatização.

Esse argumento de oposição à máquina pensante comprova a inaptidão desta ao legal reasoning, o que, por si só, inviabiliza sua tomada de decisão nos parâmetros do processo democrático. Indiscutível, pois, o fato de que os princípios constitucionais é que determinam o caráter democrático no processo decisório. Assim, se os computadores, no momento em que decidem sobre determinada lide, são incapazes de fundamentar as razões pelas quais interpretaram a lei daquela forma, e, ainda, os motivos que os levaram a deixar de acolher a tese sucumbente, resta configurada a ofensa ao princípio da fundamentação das decisões.

De mais a mais, consoante fora anteriormente abordado, os princípios do contraditório e da fundamentação das decisões estão interligados, agindo como pressuposto um do outro. Este fato se dá em razão da exigência, nos parâmetros constitucionais-democráticos, da decisão jurisdicional fundamentar, tanto o motivo pelo qual acolheu a tese vitoriosa, bem como deixou de acolher a tese sucumbente - dando a necessária atenção à garantia do contraditório. Sendo a máquina inapta ao legal reasoning, o que fora comprovado através do argumento de Searle (quarto chinês), o seu emprego no processo decisório, quando no intuito de moldar o dispositivo de qualquer dos atos do juiz, ofende as importâncias dos artigos 93, inciso IX e, consequentemente, $5^{\circ}$, inciso LV, ambos da Constituição da República Federativa do Brasil (BRASIL, 1988).

Conclui-se, portanto, que o emprego da tecnologia destinado à atividade que encerra a função jurisdicional - qual seja, decidir - desobedece aos seus principais desdobramentos: a subjetividade das relações humanas, a objetividade dos critérios de julgamento e a força normativa principiológica do neoconstitucionalismo. 


\section{PLATAFORMA RADAR - SOFTWARE DE AUTOMATIZAÇÃO DAS DECISÕES JURISDICIONAIS DE COMPETÊNCIA DO TJMG}

Desde o ano de 2012 que o Tribunal de Justiça do Estado de Minas Gerais, no intuito de promover os princípios da razoável duração do processo e da segurança jurídica, vem desenvolvendo sistemas cognitivo-computacionais (VILELA, 2020). E, dentre estes, evidenciar-se-á, neste momento, a ferramenta denominada Radar.

A Plataforma Radar é instalada com o objetivo de complementar o Sistema Ágil (VILELA, 2020). Este último visa o reconhecimento de movimentação anômala na distribuição de demandas nas comarcas, de modo a apontar eventuais desproporções em determinado lapso temporal. Ou seja, este sistema cuida de expor a média habitual na distribuição, indicando potenciais aumentos no ajuizamento de feitos de naturezas específicas e qual o percentual destes em comparação com a média habitual.

Tal ferramenta, portanto, através da inteligência artificial, identifica a desvirtuação no que tange ao ajuizamento de ações com temática específica nas comarcas, de modo a emitir um alerta, que possibilita a uniformização das decisões para os processos de pedidos e causa de pedir considerados "idênticos".

Por seu turno, a Plataforma Radar representa um novo paradigma no que diz respeito às pesquisas textuais, que são realizadas através de dados processuais armazenados de forma não relacional (VILELA, 2020). Entende-se, através desta informação, que este software proporcionará aos assessores e desembargadores do Tribunal de Justiça mineiro a execução de buscas inteligentes por meio de palavras-chave no interior de peças jurídicas em processos que tramitam eletronicamente, facilitando a realização dos votos.

Entretanto, insta ressaltar que a função da ferramenta ora tratada não se resume somente às buscas textuais inteligentes. A Plataforma Radar é capaz de identificar recursos que considera possuir pedidos e causas de pedir "idênticos", de maneira a destiná-los a um voto genéricopadrão elaborado por algum dos Desembargadores que compõem o Tribunal de Justiça do Estado de Minas Gerais. Segundo consta no website deste órgão do Poder Judiciário, na primeira vez em que foi aplicado (em novembro de 2018), o Sistema Radar julgou, de uma só vez, duzentos e oitenta processos (MINAS GERAIS, 2020).

Findo o estudo acerca do software Radar, implementado pelo Tribunal de Justiça do Estado de Minas Gerais, entende-se que a força normativa principiológica do neoconstitucionalismo fora ofendida, uma vez que demandas individuais são julgadas colegiadamente pela máquina, de maneira genérica e sem análise detida dos autos, ofendendo o princípio da indelegabilidade da função jurisdicional. Ainda quanto aos princípios previstos na Constituição da República de 1988, há de se averiguar a desobediência à fundamentação das decisões judiciais e, consequentemente, o contraditório. Isso, pois, é impossível que haja a fundamentação das decisões nos moldes democrático-processuais pela máquina - que, como visto alhures, é incapaz de legal reasoning. A máquina, através dos algoritmos é capaz de calcular, e não de entender a essência dos procedimentos que realiza.

De mais a mais, sem o atento exame do caso concreto, resta ignorada a subjetividade das relações humanas, ao passo que, como a máquina fora a prolatora da decisão de inúmeros processos, a objetividade dos critérios de julgamento imposta pela LINDB também fora violada. Conclui-se, nesta linha de raciocício, que os três elementos entendidos como desdobramentos da função jurisdicional foram desrespeitados pela tomada de decisão via Plataforma Radar.

\section{CONSIDERAÇÕES FINAIS}


Artigo: A (in)constitucionalidade da aplicação da inteligência artificial no processo decisório via plataforma radar

O objetivo do presente artigo se deu na averiguação quanto à constitucionalidade da proposta de utilização do software Radar para a prolação de decisões, considerando que a função jurisdicional é composta pela subjetividade das relações humanas, objetividade dos critérios de julgamento e força normativa principiológica do neoconstitucionalismo.

Apresentado o tema, o segundo capítulo cuidou de explanar acerca da função jurisdicional à luz do Estado Democrático de Direito, dando ênfase à sua evolução histórica, e, consequentemente, na relevância da imersão no caso concreto antes de julgá-lo, nas formas legais previstas, em rol taxativo, para a prolação de uma decisão jurisdicional, e o dever constitucional de fundamentação, imposto no artigo 93, inciso IX, da Constituição da República.

Para introduzir a problemática proposta pela presente pesquisa, no terceiro capítulo foi apresentado o tema da inteligência artificial como subárea da Ciência da Computação, estudando-se o processo de automatização.

Posteriormente, no intuito de dirigir a abordagem ao rumo da ciência do Direito, o quarto capítulo explorou as razões perante as quais acredita-se que foram implementadas ferramentas de inteligência artificial na esfera jurídica.

A fim de conectar o estudo do Direito Constitucional, primeiramente abordado, com a temática da Ciência da Computação, em seguida trabalhada, o quinto capítulo demonstra a dialocidade lógica entre os desdobramentos da função jurisdicional e as possíveis consequências por estes sofridas quando da implementação da inteligência artificial com função decisória.

Realizando um recorte temático, que direcionou a pesquisa ao Poder Judiciário do Estado de Minas Gerais, o sexto capítulo cuidou de trabalhar as nuances do software implementado no Tribunal de Justiça mineiro. Deste estudo, entendeu-se que o sistema utilizado pelo órgão em questão, recebe, por delegação, a função jurisdicional.

Assim, pôde-se concluir que o emprego da inteligência artificial no processo decisório, se para fins meramente instrumentais, configura plausível alternativa para otimizar o trabalho do magistrado. Por outro lado, o uso da computação cognitiva, quando destinado à delineação dos moldes do teor decisório, corrompe a função jurisdicional à luz do Estado Democrático de Direito, uma vez que afronta os três desdobramentos que se entende compô-la.

\section{REFERÊNCIAS}

ABI-CHAHINE, Paula Aparecida. O problema da litigiosidade de massa: análise crítica acerca das técnicas que conferem repercussão coletiva ao julgamento de demandas individuais. 2015. Dissertação (Mestrado em Direito - Universidade de São Paulo, São Paulo, 2015. Disponível em: https://www.teses.usp.br/teses/disponiveis/2/2137/tde-09122015134129/publico/Dissertacao_versao_parcial_Paula_AbiChahine.pdf. Acesso em: 23 fev. 2021.

ÁVILA, Humberto. Teoria dos princípios da definição à aplicação dos princípios jurídicos. 12 ed ampl. São Paulo: Editora Malheiros, 2011.

BRANDOM, Robert. Articulating reasons: na introduction to inferentialism. Cambridge, Mass: Harvard University Press, 2009.

BRASIL. Supremo Tribunal Federal. Ministra Cármen Lúcia anuncia início de funcionamento do Projeto Victor, de inteligência artificial. Notícias TSF, Brasília, 30 ago. 2018. Disponível 
em: http://www.stf.jus.br/portal/cms/verNoticiaDetalhe.asp?idConteudo=388443. Acesso em: 22 fev. 2021.

BURMANN, Alexandre; PEREIRA, Rafael. A inteligência artificial como instrumento para garantir segurança jurídica e proteção ambiental nos processos de licenciamento. Revista Páginas de Direito, Porto Alegre, ano 20, nº 1408, abr. 2020.

DINIZ, Maria Helena. Compêndio de introdução à ciência do direito. 15. ed. [S. 1.]: Editora Saraiva, 2003.

FIORATTO, Débora Carvalho; BRÊTAS, Ronaldo de Carvalho Dias. A conexão entre os princípios do contraditório e da fundamentação das decisões no Estado democrático de direito. Revista Eletrônica do Curso de Direito - PUC Minas Serro, Serro, v.01, 2010.

JUNGER, Alex Paubel et al. A geração imediatista e a comunicação audiovisual. Research Society and Development, v. 7, n. 11, p. 5711441, May 2018.

LEMES, Larissa Machado. Duração razoável do processo e perspectiva kairológica de tempo: uma análise da teoria do não prazo. 2019. Trabalho de Conclusão de Curso (Graduação em Direito) - Pontifícia Universidade Católica de Minas

MARINONI, Luiz Guilherme. Curso de processo civil: volume 1: teoria geral do processo. São Paulo: Revista dos Tribunais, 2006.

MARTINS, Anne Shirley de Oliveira Rezende; DOS REIS, João Paulo Alves; ANDRADE, Lucas Silva. Novo humanismo, justiça cidadã, administração pública gerencial, poder judiciário e inteligência artificial. Virtuajus, v. 5, n. 8, p. 61-83, 2020

MEDEIROS, Nathália Roberta Fett Viana de. Uso da inteligência artificial no processo de tomada de decisões jurisdicionais: uma análise sob a perspectiva da teoria normativa da comparticipação. 2019 Dissertação (Mestrado) - Pontifícia Universidade Católica de Minas Gerais, Belo Horizonte, 2019. Disponível em:

http://www.biblioteca.pucminas.br/teses/Direito_MedeirosNRFV_1.pdf. Acesso em: $22 \mathrm{fev}$. 2021.

MINAS GERAIS. Tribunal de Justiça do Estado. TJMG utiliiza inteligência artificial em julgamento virtual. Portal TJMG, Notícias, Belo Horizonte, 7 nov. 2018. Disponível em: https://www.tjmg.jus.br/portal-tjmg/noticias/tjmg-utiliza-inteligencia-artificial-emjulgamento-virtual.htm\#.XcChotVKiUk. Acesso em: 22 fev. 2021.

MONTESQUIEU. Do espírito das leis. 2. São Paulo Grupo Almedina, 2017. p. 158

NUNES, Dierle; BAHIA, Alexandre; PEDRON, Flávio Quinaud. Teoria geral do processo: com comentários sobre a virada tecnológica no direito processual. Salvador: Editora JusPodivm, 2020.

OLIVEIRA, Thaís de Bessa Gontijo de; CARDOSO, Renato César. Consiliência e a possibilidade do neurodireito: da desconfiança à reconciliação disciplinar. Revista Brasileira de Políticas Públicas, Brasília, v. 8, n. 2, 2018. 
PARFIT, Derek. On what matters: volume one. Oxford: Oxford Universitu Press, 2011.

ROSA, Alexandre Morais da; GUASQUE, Bárbara. O avanço da disrupção nos tribunais brasileiros. In: NUNES, Dierle; LUCON, Paulo Henrique dos Santos; WOLKART, Erik Navarro (Org.). Inteligência artificial e direito processual: os impactos da virada tecnológica no direito processual. Salvador: Editora JusPodivm, 2020. p. 65-75.

SILVA, José Afonso da. Curso de direito constitucional positivo. 25. ed. rev. e atual. São Paulo: Malheiros, 2005.

THEODORO JÚNIOR, Humberto. Curso de direito processual civil: volume 1: parte geral. 56. ed. Rio de Janeiro: Forense, 2015.

VALENTINI, Rômulo Soares. Julgamento por computadores? as novas possibilidades da juscibernética no século XXI e suas implicações para o futuro do direito e do trabalho dos juristas. 2017. Dissertação (Doutorado) - Universidade Federal de Minas Gerais, Belo Horizonte, 2017. Disponível em: https://repositorio.ufmg.br/bitstream/1843/BUOS-

B5DPSA/1/vers_o_completa_tese_romulo_soares_valentini.pdf. Acesso em: 22 fev. 2021.

VILELA, Afrânio. A racionalização procedimental como instrumento de melhoria da gestão judiciária e a busca pelo alcance do modelo social de processo no âmbito do Tribunal de Justiça de Minas Gerais. Belo Horizonte: TJMG, 2020. 